\title{
ANTIFUNGAL EFFECT OF ETHANOL PLANT EXTRACT ON CANDIDA SP
}

\author{
Awatif Al-Judaibi and Fozia Al-Yousef \\ Department of Biological Science, King Abdulaziz University, Jeddah, Saudi Arabia
}

Received 2014-02-14; Revised 2014-03-03; Accepted 2014-03-11

\begin{abstract}
In this study, we investigated the in-vitro antimicrobial activity of some medicinal plants in the Arabian peninsula, including Rhamnus globosa, Ocimum basilicum, Tecoma stans and Coleus forskohlii. Our results showed high inhibitory growth in yeast after treatment with $R$. globosa and O. basilicum. C. tropicalis was shown to be a sensitive strain with an inhibition of $29,28,35,25$ and $27 \mathrm{~mm}$ after treatment with $R$. globosa, R. globosa* "leaf with thorns," O. basilicum, Tecoma stans and Coleus forskohlii, respectively. Thus, our results confirmed the fungicidal effect of $O$. basilicum and $R$. globosa with a 20 and $30 \%$ reduction in CFU compared with the starting inoculums in the time-kill.
\end{abstract}

Keywords: Antifungal, Medicinal Plant Extracts, Candida sp., MIC, Effect

\section{INTRODUCTION}

Candida albicans is a common microflora in humans and an opportunistic fungal infection, which is often found in compromised immune systems and the overgrowth of this yeast causes candidiasis. In addition, these fungal pathogens have become increasingly important over the past 20 years; with the success of modern medical practices, this provides hope for the survival of weakened and immunosuppressed patients (Kourkoumpetis et al., 2010; Kothavade et al., 2010; Tanushree et al., 2010; Dalirsani et al., 2011). Treatment of pathogenic fungi involves antifungal medications, which include several groups. However, fungal and human cells are similar at the molecular level and thus it is difficult to identify medicines that target fungi without affecting human cells. Consequently, the side effects of these drugs include allergic reactions, liver damage and altered estrogen levels. Moreover, improper use of antifungals can be life threatening (McMichael and Hordinsky, 2008). Thus, new antifungal drugs that are safer and more effective are needed.

Natural products derived from medicinal plants are among the safest sources of new medications and Corresponding Author: Awatif Al-Judaibi, Department of Biol antifungal drugs. Several studies have investigated natural products and essential oils with antimicrobial and antifungal effects. For example, in a study of alcoholic curry leaves, a maximum zone of inhibition on Candida albicans following treatment with aqueous tea leaves was observed. However, other plant extracts such as alcoholic onion leaves, alcoholic tea leaves, alcoholic onion bulb, alcoholic aloe vera and alcoholic mint leaves inhibited the growth of Candida albicans, but to a lesser extent (Doddanna et al., 2013). Salvia officinalis (L.) demonstrated less inhibitory effects against $C$. albicans or $C$. tropicalis and the root extracts of Labisia pumila showed a higher activity in response to Candida sp. compared with leaf extracts (Celi Garcia et al., 2012; Karimi et al., 2013). In a study on Chinese medicinal plants, water, ethanol, acetone and n-hexane extracts for each plant were tested on $C$. albicans, as well as extracts of Pseudolarix kaempferi Gord., acetone extract of Sophora flavescens Ait., ethanol, acetone and hexane extracts of Pogostemon cablin (Blanco) Benth. and Alpinia officinarum hance, hexane extract of Eugenia caryophyllata Thunb. ethanol and acetone extracts of Melia toosendan Sieb. et Zucc. and Polygonum hydropiper L., which showed an inhibition of more than 
$50 \%$ of $C$. albicans growth and was comparable to miconazole in some cases (Liu et al., 2012).

In this study, the objective was to investigate the antifungal activity of ethanol extracts of some medicinal plants in the Arabian Peninsula. These medicinal plants included Rhamnus globosa, Ocimum basilicum, Tecoma stans and Coleus forskohlii.

\section{MATERIALS AND METHODS}

\subsection{Fungi Studies}

The examined fungi included Candida albicans ATCC CA 10231 and C. tropicalis ATCC CT 2697, which were prepared as inocula by obtaining $100 \mu \mathrm{L}$ of each yeast containing $1 \times 10^{5}-5 \times 10^{5}$ (cfu) and inoculating onto Mueller-Hinton agar (OXOID CM 337).

\subsection{Plant Studies and Extract Preparation}

The plants were collected from different locations in the Arabian Peninsula. They were identified in the Botany section at the biology department, faculty of science, KAU as Rhamnus globosa, Ocimum basilicum, Tecoma stans and Coleus forskohlii. The plant leaves, except $R$. globosa, which consisted of two types of extracts (leaves and leaves with thorns) were washed several times with distilled water, spread onto plates and dried at $40^{\circ} \mathrm{C}$. After drying, the samples were grounded and solubilized with ethanol solvent at $10 \mathrm{mg} \mathrm{mL}^{-1}$. The mixtures were maintained on a shaker at $120 \mathrm{rpm}$ at $30^{\circ} \mathrm{C}$ for $24 \mathrm{~h}$ and then filtered using Whatman No. 1 filter paper. The samples were dried under a reduced pressure at $40^{\circ} \mathrm{C}$ and the thick deposits obtained were used as crude extracts (Vijayakumar et al., 2013).

\subsection{Antifungal Assays}

The antimicrobial activity of each crude plant extract was determined in vitro in response to the Candida species. The activities were measured using disc diffusion and broth dilution methods, as previously described by the Clinical and Laboratory Standards Institute (CLSI; formerly known as the National Committee for Clinical Laboratory Standards) (NCCLS, 2004; Fothergill, 2011).

Each thick deposit extract was dissolved in Dimethylsulfoxide (DMSO) at $50 \mu \mathrm{g} \mathrm{mL}^{-1}$ and filtered through a $0.22 \mu \mathrm{m}$ pore filter (Millipore, Billeria, MA). The antibacterial activities of each extract were investigated by disc diffusion using filter paper discs (1-mm diameter impregnated with $100 \mu \mathrm{L})$, which were then placed on the pre-inoculated agar surface. Negative controls were prepared with the same solvent. Plates were then incubated at $35^{\circ} \mathrm{C}$ for $48 \mathrm{~h}$ and the inhibitory zones of each disc were measured. All tests were performed in triplicate.

\subsection{Minimum Inhibitory Concentration (MIC) and Minimum Fungicidal Concentration (MFC)}

Extracts that inhibited the growth of bacteria were investigated to determine the MIC and MFC using a broth-microdilution method. The yeast were cultured overnight on mueller-hinton agar and then resuspended in $1 \mathrm{~mL}$ mueller-hinton broth (OXOID $\mathrm{CM} 405)$ to obtain a final concentration of $100 \mathrm{cfu}$ $\mathrm{mL}^{-1}$. Each extract was serially diluted with muellerhinton broth using methods approved by the National Committee for Clinical Laboratory Standards (M27A) (NCCLS, 1997). After incubation, the MIC was determined as the lowest concentration of extract for which there was no visible growth compared with the control (CLSI, 2008; 2007). The MFC was determined by inoculating $0.1 \mathrm{~mL}$ of negative growth in MIC onto sterile SDA (OXOID) plates. The plates were incubated at $35^{\circ} \mathrm{C}$ for $48 \mathrm{~h}$. The lowest concentration of plant extract that did not demonstrate growth of the tested organisms was considered the MFC; the negative control was a plate grown with media only (Ernst et al., 2002; Wiegand et al., 2008).

\subsection{Time-Kill Determination}

Liquid cultures $(1 \mathrm{~mL})$ were diluted to an initial inoculum of $2 \times 10^{5}-5 \times 10^{5} \mathrm{CFU} / \mathrm{mL}$ in Mueller-Hinton broth and R. globosa, O. basilicum, T. stans and $C$. forskohlii were added at one-half and one and two times the MICs. The cultures were incubated for 0, 2, 4, 8, 12 and $48 \mathrm{~h}$ at $30^{\circ} \mathrm{C}$. After each time point, $50 \mu \mathrm{L}$ aliquots were obtained from the cultures, plated onto the SDA and incubated at $35^{\circ} \mathrm{C}$ for $48 \mathrm{~h}$. Visible colonies were read using an Interscience scan 500 colony counters and each treatment was performed in triplicate (Nostro et al., 2000; Lewis et al., 2002).

\subsection{Statistical Analysis}

The results were analyzed by paired-samples $t$-test using the IBM SPSS 20 statistical software to compare the mean values of each treatment. The results are expressed as means \pm SE. Probability levels of less than 0.01 were considered highly significant. 


\section{RESULTS}

Investigation of new antifungal agents from natural sources is a major field of research and the results of these studies have identified several new sources of plant medicines and their synthetic compounds. As shown in Table 1, high inhibitory growth of the tested yeast was observed after treatment with $R$. globosa and O. basilicum and C. tropicalis was shown to be a sensitive strain with an inhibition of 29, 28, 35, 25 and $27 \mathrm{~mm}$ after treatment with $R$. globosa, $R$. globosa* "leaf with thorns," $O$. basilicum, Tecoma stans and Coleus forskohlii, respectively. The ethanol extract of the R. globosa leaf and R. globosa leaf with thorns showed that there was no significant difference between these bacteria on yeast growth inhibition and the highest inhibitory effect was observed in $C$. tropicalis, with an inhibition of $29 \mathrm{~mm}$ for $R$. globosa.

The MIC and MFC values are shown in Table 2 and 3. According to these results, the highest MICs were $8 \mu \mathrm{L} \mathrm{mL}^{-1}$ and $4 \mu \mathrm{L} \mathrm{mL}^{-1}$, which were obtained by treatment with $O$. basilicum on $C$. albicans and $C$. tropicalis, respectively. In contrast, the lowest MICs were obtained by treatment with Tecoma stans extracts on the tested yeast. The most sensitive yeast was $C$. tropicalis with MICs of $4,8,4,16$ and $8 \mu \mathrm{L}$ $\mathrm{mL}^{-1}$ after treatment with $R$. globosa, R. globosa* "leaf with thorns," O. basilicum, Tecoma stans and Coleus forskohlii, respectively. The MFCs were approximate in most plant extracts. Most fungicidal concentrations were affected by treatments with $O$. basilicum on $C$. albicans and $C$. tropicalis with values of 32 and $16 \mu \mathrm{L} \mathrm{mL}^{-1}$, respectively and the fungicidal extract concentrations of Tecoma stans increased to 128 and $128 \mu \mathrm{L} \mathrm{mL} \mathrm{m}^{-1}$, for $C$. albicans and $C$. tropicalis, respectively.

The concentration of MICs and MBCs reflected the kill-times of the tested yeast. As shown in Fig. 1 and 2, the kill-time of one-half MIC, MIC and two MIC of each plant extract had no significant differences. The tested yeast had an endpoint of kill-times at a concentration of two MICs within $4 \mathrm{~h}$ except $T$. stans and C. forskohlii, which had an endpoint of kill-time of $12 \mathrm{~h}$ and $8 \mathrm{~h}$, respectively. The CFUs of the tested bacteria decreased after $2 \mathrm{~h}$ and continued to decrease until they reached the kill-time. The fungicidal endpoint was not reached at a concentration of onehalf MIC and extracts of R. globosa, O. basilicum and C. forskohlii resulted in 20,30 and $10 \%$ reduction in CFU from the starting inoculums, respectively.

Table 1. Inhibition of candida sp. growth (mm) after $48 \mathrm{~h}$ of incubation with $100 \mu \mathrm{L}$ plants ethanol extracts

\begin{tabular}{|c|c|c|c|c|c|}
\hline & \multicolumn{5}{|l|}{ Mean \pm SE } \\
\hline & $\begin{array}{l}\text { Rhamnus } \\
\text { globosa }\end{array}$ & R. globosal & $\begin{array}{l}\text { Ocimum } \\
\text { basilicum }\end{array}$ & $\begin{array}{l}\text { Tecoma } \\
\text { stans }\end{array}$ & $\begin{array}{l}\text { Coleus } \\
\text { forskohlii }\end{array}$ \\
\hline Candida albicans & $26 \pm 0.11667 * *$ & $25 \pm 0.17638 * *$ & $32 \pm 0.09280 * *$ & $24 \pm 0.23154 *$ & $25 \pm 0.22850 *$ \\
\hline C. tropicalis & $29 \pm 0.11667 * *$ & $28 \pm 0.08333 * *$ & $35 \pm 0.10408 * *$ & $25 \pm 0.06009 * *$ & $27 \pm 0.32830 *$ \\
\hline
\end{tabular}

R. globosa*: The leaf and thorns

Table 2. MIC $(\mu \mathrm{L} / \mathrm{m})$ of Candida growth after $48 \mathrm{~h}$ of treated with serial concentrations of plants methanol extracts

\begin{tabular}{|c|c|c|c|c|c|}
\hline & $\begin{array}{l}\text { Rhamnus } \\
\text { Globosa }\end{array}$ & R. globosa* & $\begin{array}{l}\text { Ocimum } \\
\text { basilicum }\end{array}$ & $\begin{array}{l}\text { Tecoma } \\
\text { stans }\end{array}$ & $\begin{array}{l}\text { Coleus } \\
\text { forskohlii }\end{array}$ \\
\hline Candida albicans & 16 & 16 & 8 & 64 & 32 \\
\hline C. tropicalis & 4 & 8 & 4 & 16 & 8 \\
\hline
\end{tabular}

R. globosa*: The leaf and thorns

Table 3. MFC $(\mu \mathrm{L} / \mathrm{m})$ of Candida growth after $48 \mathrm{~h}$ of incubation in SDA

\begin{tabular}{llllll}
\hline & $\begin{array}{l}\text { Rhamnus } \\
\text { globosa }\end{array}$ & R. globosa* & $\begin{array}{l}\text { Ocimum } \\
\text { basilicum }\end{array}$ & $\begin{array}{l}\text { Tecoma } \\
\text { stans }\end{array}$ & $\begin{array}{l}\text { Coleus } \\
\text { forskohlii }\end{array}$ \\
\hline Candida albicans & 32 & 64 & 32 & 128 & 64 \\
C. tropicalis & 32 & 64 & 16 & 128 & 64 \\
\hline
\end{tabular}

R. globosa*: The leaf and thorns 
Awatif Al-Judaibi and Fozia Al-Yousef / American Journal of Agricultural and Biological Sciences 9 (3): 277-283, 2014

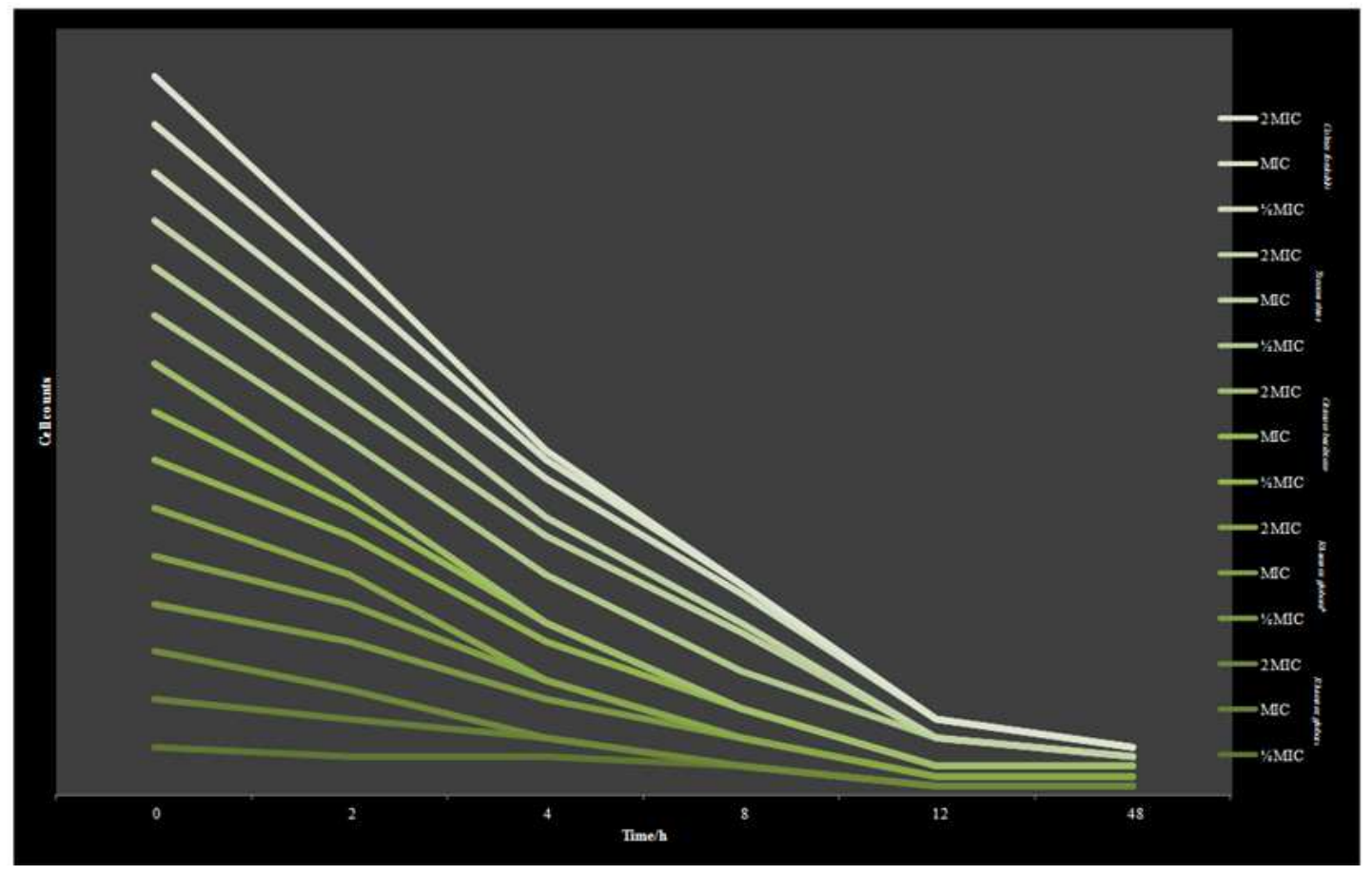

Fig. 1. Time-kill of Candida albicans within incubation in variety periods with plant extracts

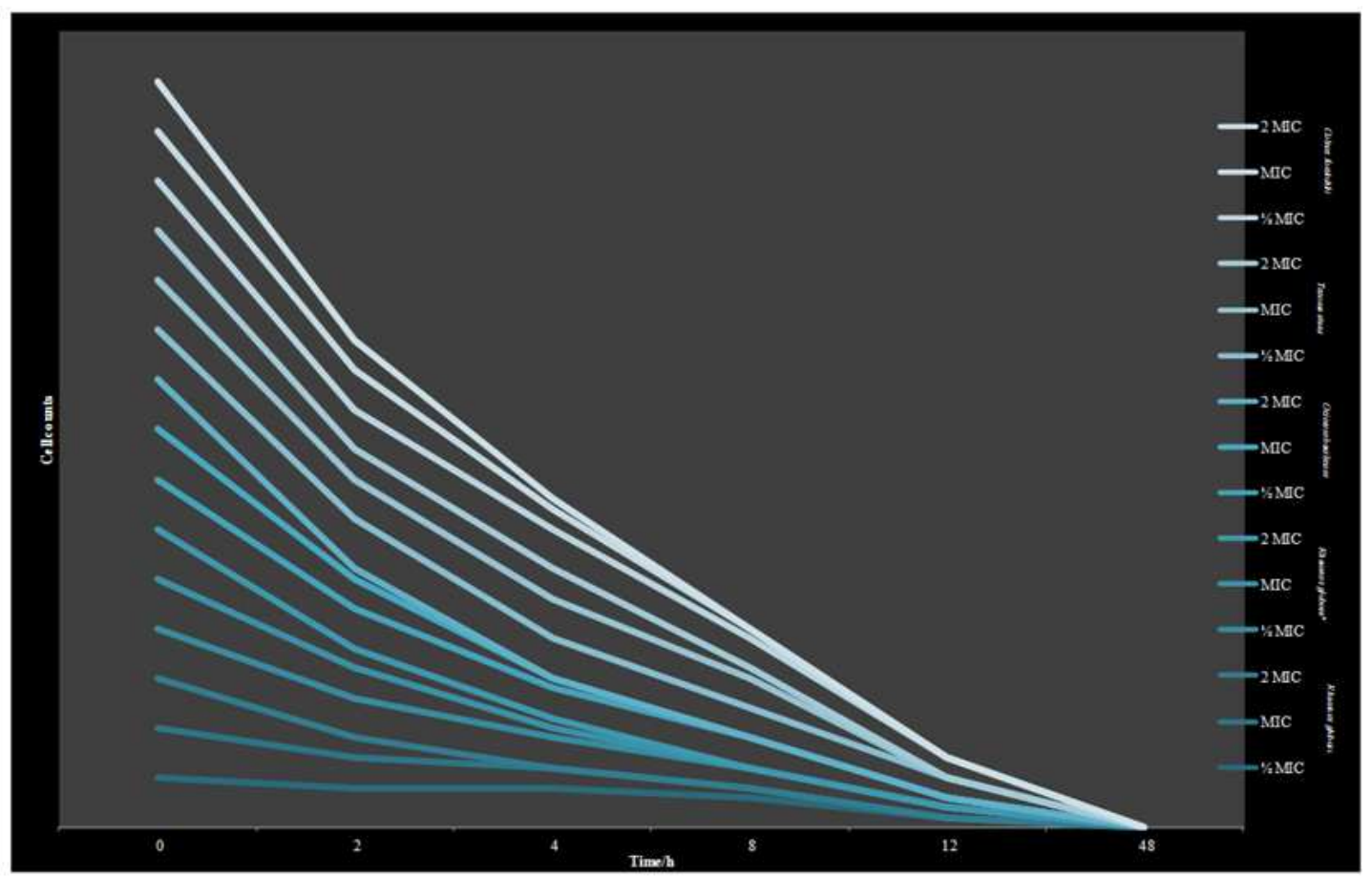

Fig. 2. Time-kill of Candida tropicalis within incubation in variety periods with plant extracts 


\section{DESSCUSION}

Previous studies have performed screens on the antimicrobial activity of extracts from plants. On the basis of these studies, it was concluded that diethyl ether extracts were the most efficient antimicrobial compounds and this activity was more pronounced against grampositive bacteria (Nostro et al., 2000). Our results on ethanol extracts were consistent with the results of several studies on alcoholic and non-alcoholic plant extracts. A previous study of alcoholic curry leaves demonstrated the strongest growth inhibition of $C$. albicans followed by aqueous tea leaves, alcoholic onion, tea, mint leaves extracts and alcoholic onion bulb and aloe vera extracts (Duarte et al., 2005). Moreover, a study of Traditional Chinese Medicine (TCM) and Chinese folk medicine demonstrated antifungal activity against Candida albicans; however, out of 58 extracts examined, two plant extracts, Codonopsis pilosula and Tussilago farfara, showed high inhibitory effects against C. albicans (Karimi et al., 2013; Zhang et al., 2013). In addition, a recent study on six natural commodities and four commercial medicines against $C$. albicans revealed that Mayaca extracts could act as a potential antifungal agent for oral thrush caused by C. albicans (Reena et al., 2013). Furthermore, extracts of Althaea officinalis and Matricaria recutita and Combretum molle, Piper capense, Solanum aculeastrum, Syzygium cordatum and Zanthoxylum davyi have a fungicidal effect on C. albicans (Steenkamp et al., 2007; Shakib et al., 2013). However, a study on essential oils and ethanolic extracts from the leaves and roots of 35 medicinal plants commonly used in Brazil, were tested for an antifungal effect on $C$. albicans and essential oils from 13 plants showed antifungal activity, including Aloysia triphylla, Anthemis nobilis, Cymbopogon martini, Cymbopogon winterianus, Cyperus articulatus, Cyperus rotundus, Lippia alba, Mentha arvensis, Mikania glomerata, Mentha piperita, Mentha sp., Stachys byzantina and Solidago chilensis. Moreover, the ethanol extract was not effective at any of the concentrations tested (Duarte et al., 2005).

Several studies have been performed to determine the MICs and MFCs and time-kill of medicinal plant extracts, including studies investigating the MICs and MFCs of medicinal plant extracts, including Pinus monticola, Taxus baccata, Phyllanthus debilis and Plectranthus amboinicus, Catharanthus roseus, Nerium oleander, Tabernaemontana divaricata, Etlingera elatior, Rhizoma coptidis, Radix stemonae, Radix sophorae flavescentis, Ajuga pseudoiva (L.), Foeniculum vulgare, Trachyspermum ammi, Cuminum cyminum,
Syzygium aromaticum, Cinnamomum tamala and 54 species of Orchidaceae from Brazil on species of Candida and other fungi. Their results were consistent with our results (Vaz et al., 2009; Zamany et al., 2011; Ben Mansour et al., 2013; Khan et al., 2013; Khodavandi et al., 2013; Wankhede et al., 2013).

The high antimicrobial effect of medicinal plant extracts may be due to the compensation between the secondary metabolic compounds in plant tissues. Results of the phytochemical screening on medicinal plants showed that the antimicrobial activity was most likely due to the compounds reduced from plant metabolism, such as flavonoids, terpenes, alkaloids, tannins, the hydroxyl group and phenol; 1,8-cineole, geranial, germacrene-D, limonene, linalool, fatty acids, esters and menthol; and essential oils, such as yarrow, carvacrol, thymol, glycosides, tannins, saponins and steroids (Gregory et al., 2009; Choudhury et al., 2013; Jadha et al., 2013; Joshua and Takudzwa, 2013; Mulyono et al., 2013).

\section{CONCLUSION}

In conclusion, we highlighted the antifungal activity of ethanol extracts of Rhamnus globosa, Ocimum basilicum, Tecoma stans and Coleus forskohlii. These results confirmed the traditional uses of $R$. globosa as medicinal plants. In addition, extracts of $O$. basilicum primarily produced fungicidal effects, with a limited number of observed growths, which was consistent with the MIC and MBC and kill-time of both plant extracts.

\section{REFERENCES}

Ben Mansour, M., R. Balti, L. Rabaouia, A. Bougatefc and M. Guerfela, 2013. Chemical composition, Angiotensin I-Converting Enzyme (ACE) inhibitory, antioxidant and antimicrobial activities of the essential oil from south Tunisian Ajuga pseudoiva Rob. Lamiaceae. Process Biochem, 48: 723-729. DOI: 10.1016/j.procbio.2013.02.022

Celi Garcia, C.S., M.R. Ely, R.A. Wasum, B.C. De Antoni Zoppa and C.W.G. Ângela Neves et al., 2012. Assessment of Salvia officinalis (L.) hydroalcoholic extract for possible use in cosmetic formulation as inhibitor of pathogens in the skin. J. Basic Applied Pharmaceutical Sci. Rev. Ciênc Farm Básica Apl., 33: 509-514.

Choudhury, S., L. Sharani and M.P. Sinha, 2013. Pharmacological efficacy of some medicinal plants used for treatment of gastrointestinal diseases. IQJES, Special, 3: 111-116. 
CLSI, 2007. Performance standards for antimicrobial susceptibility testing. Proceedings of the 17 th Information Supplement. CLSI Document M100S17 (M2-A7 and M7-A7) 27(1). Clinical and Laboratory Standards Institute, Wayne, Pa.

CLSI, 2008. Reference Method for Broth Dilution Antifungal Susceptibility Testing of Yeasts. 3rd Edn., Clinical and Laboratory Standards Institute, Wayne.

Dalirsani, Z., M. Adibpour, M. Aghazadeh, M. Amirchaghmaghi and F. Falaki et al., 2011. In Vitro comparison of inhibitory activity of 10 plant extracts against Candida Albicans. Australian J. Basic Applied Sci., 5: 930-935.

Doddanna, S.J., S. Patel, M.A. Sundarrao and R.S. Veerabhadrappa, 2013. Antimicrobial activity of plant extracts on Candida albicans: An in vitro study. Ind. J. Dent Res., 24: 401-5. DOI: 10.4103/0970-9290.118358

Duarte, M.C.T., G.M. Figueira, A. Sartoratto, V.L.G. Rehder and C. Delarmelina, 2005a. AntiCandida activity of Brazilian medicinal plants. J. Ethnopharmacol., 97: 305-311. DOI: 10.1016/j.jep.2004.11.016.

Ernst, E.J., E.E. Roling, C.R. Petzold, D.J. Keele and M.E. Klepser, 2002. In vitro activity of micafungin (FK-463) against Candida spp.: Microdilution, timekill and postantifungal-effect studies. Antimicrobial Agents Chemotherapy, 46: 3846-3853. DOI: 10.1128/AAC.46.12.3846-3853.2002

Fothergill, A.W., 2011. Antifungal Susceptibility Testing: Clinical Laboratory and Standards Institute (CLSI) Methods. In: Intraction of Yeast, Moulds and Antifungal Agents, Hall, G.S. (Ed.)., Humana Press, New York, ISBN-10: 1597451347, pp: 65-74.

Gregory, M., K.P. Vithalrao, G. Franklin and V. Kalaichelavan, 2009. Anti-ulcer (ulcer-preventive) activity of Ficus arnottiana Miq. (Moraceae) leaf methanolic extract. Am. J. Pharmacol. Toxicol., 4: 89-93. DOI: 10.3844/ajptsp.2009.89.93

Jadha, S., R. Shah, M. Bhave and E.A. Palombo, 2013. Inhibitory activity of yarrow essential oil on Listeria planktonic cells and biofilms. Food Control, 29: 125-130. DOI: 10.1016/j.foodcont.2012.05.071

Joshua, M. and M. Takudzwa, 2013. Antibacterial properties of Mangifera indica on Staphylococcus aureus. Afr. J. Clin. Exp. Microbiol., 14: 62-74. DOI: 0.4314/ajcem.v14 i2.4
Karimi, E., H.Z.E. Jaafar and S. Ahmad, 2013. Antifungal, anti-inflammatory and cytotoxicity activities of three varieties of labisia pumila benth: From microwave obtained extracts. BMC Complementary Alternative Med., 13: 20-20. DOI: 10.1186/1472-6882-13-20

Khan, D.M., L. Bernaitis, K.L. Shobha, M. Ashok and P.S. Revathi, 2013. Antifunagal activity of taxus baccata phyllanthus debilis plectranthus amboinicus against Candida species of clinical origin. Int. J. Biol. Pharmaceutical Res., 4: 386-389.

Khodavandi, A., N.A. Binti Tahzir, P.W. Cheng, P.Y.V. Chen and F. Alizadeh et al., 2013. Antifungal activity of rhizome coptidis and alpinia galangal against Candida species. J. Pure Aplied Microbiol., 7: 1725-1730.

Kothavade, R.J., M.M. Kura, A.G. Valand and M.H. Panthaki, 2010. Candida tropicalis: Its prevalence, pathogenicity and increasing resistance to fluconazole. J. Med. Microbiol., 59: 873-880. DOI: 10.1099/jmm.0.013227-0

Kourkoumpetis, T., D. Manolakaki, G.C. Velmahos, Y. Chang and B. Alam et al., 2010. Candida infection and colonization among non-trauma emergency surgery patients. Virulence, 1: 359-366. DOI: 10.4161/viru.1.5.12795

Lewis, R.E., D.J. Diekema, S.A. Messer, M.A. Pfaller and M.E. Klepser, 2002. Comparison of Etest, chequerboard dilution and time-kill studies for the detection of synergy or antagonism between antifungal agents tested against Candida species. J. Antimicrobial Chemotherapy, 49: 345-351. DOI: 10.1093/jac/49.2.345

Liu, Q., W. Luyten, K. Pellens, Y. Wang, W. Wang and K. Thevissen et al., 2012. Antifungal activity in plants from Chinese traditional and folk medicine. J. Ethnopharmacol., 143: 772-778. DOI: 10.1016/j.jep.2012.06.019

McMichael, A.J. and M.K. Hordinsky, 2008. Hair and Scalp Diseases. 1st Edn., Informa Healthcare, Boca Raton, ISBN-10: 1574448226, pp: 319.

Mulyono, N., B.W. Lay, L. Ocktreya and S. Rahayu, 2013. Antidiarrheal activity of apusbamboo (Gigantochloa apus) leaf extract and its bioactive compounds. Am. J. Microbiol., 4: 1-8. DOI: 10.3844/ajmsp.2013.1.8

NCCLS, 1997. Reference method for broth dilution antifungal susceptibility testing of yeasts. Approved standard M27-A. National Committee for Clinical Laboratory Standards, Wayne, Pa. 
NCCLS, 2004. Reference method for antifungal disk diffusion susceptibility testing of yeasts; approved guideline. NCCLS document M44-A. National Committee for Clinical Laboratory Standards, Wayne.

Nostro, A., M.P. Germano, A.V. D'Angelo, A. Marino and M.A. Cannatelli, 2000. Extraction methods and bioautography for evaluation of medicinal plant antimicrobial activity. Lett. Applied Microbiol., 30: 379-384. DOI: 10.1046/j.1472765x.2000.00731.x

Reena, T., R. Prem, M.S. Deepthi, R.B. Ramachanran and S. Sujatha, 2013. Comparative effect of natural commodities and commercial medicines against oral thrush causing fungal organism of Candida albicans. Sci. J. Clin. Med., 2: 75-80. DOI: 10.11648/j.sjcm.20130203.13

Shakib, P., M. Azad Poor, P. Saeedi, G. Goudarzi and H.R. Nejad et al., 2013. Scrutinizing the antimicrobial effect of hydro alcoholic extract of Althaea officinalis (marshmallow) and Matricaria recutita (chamomile) flowers. Life Sci. J., 10: 162-166.

Steenkamp, V., A.C. Fernandes and C.E.J. Van Rensburg, 2007. Screening of Venda medicinal plants for antifungal activity against Candida albicans. South Afr. J. Botany, 73: 256-258. DOI: 10.1016/j.sajb.2006.11.003

Tanushree, D.C., R. Das and R.C. Mohanty, 2010. Differential inhibitory effects of medicinal plant extracts on proline uptake in clinically isolated three Candida spp. Nat. Sci., 8: 132-139.
Vaz, A.B.M., R.C. Mota, M.R.Q. Bomfim, M.L.A. Vieira and C.L. Zani et al., 2009. Antimicrobial activity of endophytic fungi associated with Orchidaceae in Brazil. Canad. J. Microbiol., 55: 1381-1391. DOI: 10.1139/W09-101

Vijayakumar, M., K. Priya, F.T. Nancy, A. Noorlidah and A.B. Ahmed, 2013. Biosynthesis, characterisation and anti-bacterial effect of plantmediated silver nanoparticles using Artemisia nilagirica. Indust. Crops Products, 41: 235-240. DOI: 10.1016/j.indcrop.2012.04.017

Wankhede, S.B., M.M. Routh, S.B. Rajput and S.M. Karuppayil, 2013. Antifungal properties of selected plants of Apocynaceae family against the human fungal pathogen Candida albicans. Int. Current Pharmaceutical J., 2: 122-125. DOI: 10.3329/icpj.v2i7.15155

Wiegand, I., K. Hilpert and R.E.W. Hancock, 2008. Agar and broth dilution methods to determine the Minimal Inhibitory Concentration (MIC) of antimicrobial substances. Nat. Protocols, 3: 163-175. DOI: $10.1038 /$ nprot.2007.521

Zamany, A., J.J. Liu, A. Ekramoddoullah and R. Sniezko, 2011. Antifungal activity of a Pinus monticola antimicrobial peptide 1 (Pm-AMP1) and its accumulation in western white pine infected with Cronartium ribicola. Canadian J. Microbiol., 57: 667-679. DOI: 10.1139/w11-046

Zhang, L., A.S. Ravipati, S.R. Koyyalamudi, S.C. Jeong and N. Reddy et al., 2013. Anti-fungal and antibacterial activities of ethanol extracts of selected traditional Chinese medicinal herbs. Asian Pacific J. Tropical Med., 6: 673-81. DOI: 10.1016/S19957645(13)60117-0 